сфере, государственным и муниципальным служащим, а также строительному сектору экономики.

Но изменения в девелопменте в момент кризиса неоднозначны. Алена Владимирская, ведущий HR- специалист объясняет это тем, что люди, пытаясь сберечь свои деньги, вкладывают их в недвижимость, а потом на протяжении нескольких лет у них нет денежных средств, чтобы вложиться в строительство, и к тому же существует кризис в банках, поэтому с оформлением ипотек тоже возникают проблемы. В какой ситуации дальнейший прогноз становится очевиден : пострадает вся производственная цепочка, от строителя до офисных работников.

Также на ряду с специалистами технических профессий обеспечить себя рабочим местом смогут работники занятые в торговле . По-прежнему остаются высокооплачиваемые финансовые директора,( т.к. традиционно в финансовой сфере были самые высокие зарплаты) пользуются спросом менеджеры и руководители продаж.

Благоприятны прогнозы экспертов в плане трудоустройства выпускников ВУЗов. Они утверждают, что всё больше набирает оборот тенденция образований специализированных кафедр в университетах, с помощью которых студенты могли бы начать свою профессиональному деятельность, совмещая учёбу с работой.

Подведя итог, можно сказать, что по сравнению с 2017 годом, рынок труда этого года оценивается как более благоприятный. Те, кто долго сидел без дела, смогут найти себе работу. Вакансий станет больше. Только вот ждать повышения зарплаты, как минимум первые полгода, не следует.

$$
* * *
$$

1. Борисов И.А., Шарапова Н.В., Лагутина Е.Е. Особенности российского рынка труда как фактор, определяющий механизм подстройки в условиях экономического кризиса //Экономика и предпринимательство. 2016. № 12-1 (77-1). С. 812-815.

2. Особенности и современные тенденции развития рынка труда. [Электронный ресурс]. Режим доступа: http://ppt4web.ru/ehkonomika/osobennosti-i-sovremennye-tendencii-razvitija-rynka-truda.html

3. Рынок труда и демографическая ситуация в России. [Электронный ресурс]. Режим доступа: http: //www.bankreferatov.ru/referats/071FB11 ABAD55DC643257B000057182E/mikroekonomika.docx.html

4. Бухалков М.И. Организация и нормирование труда. Учебник для вузов, 4-е изд., испр. Доп. - М.: НИЦ ИНФРА-М, 2013. - 380 с.

5. Остапенко Ю.М. Экономика труда. Учебное пособие / Ю.М. Остапенко. Государственный Университет Управления. - 2-е изд., перераб. и доп. - М. : ИНФРА-М, 2011. -272 с.

\title{
Захарова И.А. \\ Совершенствование системы оценки эффективности муниципальных программ на примере муниципальной программы «Развитие образования в городе Нижнем Новгороде» на 2018-2020 годы
}

МГУ им. М.В. Ломоносова (Россия, Москва)

doi:10.18411/spc-08-04-2018-06

idsp: 000001:spc-08-04-2018-06

Программно-целевое бюджетирование, применяемое в странах Запада более полувека, пришло в российскую практику управления государственными и муниципальными финансами меньше 5 лет назад. Федеральный бюджет был впервые сформирован по программному принципу на 2014-2016гг. Переход к программному бюджету в муниципалитетах проходил неравномерно. Внедрение программно-целевого подхода сводилось к следующим ключевым целям: обеспечению взаимосвязи стратегического и бюджетного планирования; стимулированию участников бюджетного процесса к эффективному использованию денежных средств с учетом 
приоритетов и ожидаемых результатов социально -экономического развития ; а также

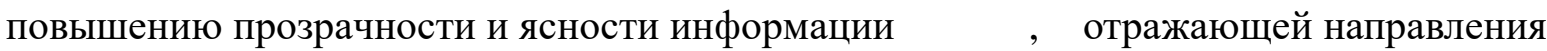
использования бюджетных средств. Главным преимуществом программного подхода является увязка результатов деятельности органов власти с деньгами. В муниципальных образованиях столкнулись с проблемой бюджетного планирования, отныне необходимо учитывать показатели эффективности исполнения программ, на основе их вносить коррективы и делать долгосрочные прогнозы. Цели и задачи органов власти увязываются с набором инициатив и мероприятий , которыми эти цели и задачи будут достигаться и показателями эффективности данных инициатив.

В целях повышения эффективности муниципальных программ проводится мониторинг и оценка самих программ. Мониторинг предполагает отслеживание на регулярной основе хода исполнения намеченных мероприятий и основан на количественных данных. Оценка подразумевает разработанную систему индикаторов эффективности реализации муниципальной программы. Если в практике российских муниципальных образований мониторинги исполнения программ осуществляются повсеместно, то что касается индикаторов эффективности - в настоящий момент единых принципов формирования нет. На стадии разработки программы, утверждения инициатив в разрезе ответственных ведомств и иных исполнителей программы разрабатываются индикаторы. Каждой цели программы должны быть поставлены индикаторы и определено их значение, которое предполагается достичь к отчетному периоду. Индикаторы могут быть выражены как в количественной, так и в качественной оценке. При разработке задач, конкретных инициатив для их достижения и индикаторов муниципальной программы следует учитывать задачи стратегического развития направления и ожидаемые результаты, указанные в стратегиях социальноэкономического развития муниципального образования. Несоответствие задач и показателей ставит под сомнение эффективность реализации системы долгосрочного и краткосрочного планирования, а также особенности реализации программ, исходя из уникальных возможностей и ресурсов муниципального образования. Автор предлагает рассмотреть на примере муниципальной программы «Развитие образования в городе Нижнем Новгороде» на 2018-2020 годы» соответствие задач и установленных показателей эффективности реализации планируемых мер Стратегии социальноэкономического развития города Нижнего Новгорода на 2017-2022 годы в части развития системы образовательных услуг.

В Стратегии обозначены следующие задачи:

1. Модернизация инфраструктуры муниципального образования.

2. Создание правовых и организационных условий для диверсификации образовательных услуг.

3. Управление муниципальным образованием.

4. Поддержка талантливых педагогов.

5. Поддержка талантливых детей.

6. Формирование у родителей личной ответственности за воспитание детей и повышение в обществе авторитета семьи как главного субъекта воспитания.

Каждой задаче соответствуют стратегические инициативы и ожидаемые результаты. На примере стратегической задачи №1 Модернизация инфраструктуры муниципального образования рассмотрим соответствие краткосрочных задач и индикаторов оценки целям, указанным в Стратегии. 
Таблииа 1

Соответствие иелевых индикаторов муниципальной программы «Развитие образования в городе Нижнем Новгороде на 2018-2020 годы задачам Направления развития системы образования в г. Нижний Новгород Стратегии

\begin{tabular}{|c|c|c|c|c|c|}
\hline $\begin{array}{c}\text { Соответствие иелевых } \\
\text { индикаторов } \\
\text { муниципальной } \\
\text { программы «Развитие } \\
\text { образования в городе } \\
\text { Нижнем Новгороде на } \\
2018-2020 \text { годьл } \\
\text { задачам Направления } \\
\text { развития системьл } \\
\text { образования в г. } \\
\text { Нижнй Новгород } \\
\text { СтратегииСтратегиче } \\
\text { ская задача } \\
\end{array}$ & $\begin{array}{c}\text { Стратегические } \\
\text { подзадачи }\end{array}$ & $\begin{array}{c}\text { Задачи } \\
\text { Подпрограм } \\
\text { м }\end{array}$ & $\begin{array}{c}\text { Индикаторы } \\
\text { подпрограммы }\end{array}$ & $\begin{array}{l}\text { Ед. } \\
\text { из } \\
\text { м. }\end{array}$ & $\begin{array}{c}2018 / 2019 / 2 \\
020\end{array}$ \\
\hline & & $\begin{array}{c}\text { Задача } \\
\text { Подпрограмм } \\
\text { ы } 1 \text { «развитие } \\
\text { дошкольного } \\
\text { образования } \\
\text { » } \\
\end{array}$ & & & \\
\hline \multirow{3}{*}{$\begin{array}{c}\text { Модернизация } \\
\text { инфраструктуры } \\
\text { муниципального } \\
\text { образования }\end{array}$} & \multirow{3}{*}{$\begin{array}{c}1 . \text { Развитие } \\
\text { инфраструктуры } \\
\text { сети } \\
\text { муниципальных } \\
\text { учреждений } \\
\text { образования в } \\
\text { соответствии с } \\
\text { территориальными } \\
\text { потребностями } \\
\text { города; } \\
\text { 2. Модернизация } \\
\text { материально- } \\
\text { технической базы } \\
\text { муниципальных } \\
\text { учреждений } \\
\text { образования; } \\
\text { Ф. Формирование } \\
\text { идеологии школы } \\
\text { как общественного } \\
\text { центра } \\
\text { микрорайона, } \\
\text { использование } \\
\text { образовательных } \\
\text { школ как } \\
\text { общественных } \\
\text { центров для } \\
\text { межпрофессиональ } \\
\text { ного и } \\
\text { межличностного } \\
\text { общения; } \\
\text { 4. Развитие } \\
\text { инклюзивного } \\
\text { образования для } \\
\text { детей с }\end{array}$} & \multirow{3}{*}{$\begin{array}{c}1 . \\
\text { Обеспечение } \\
\text { гос. гарантий } \\
\text { доступности } \\
\text { общедоступно } \\
\text { го и } \\
\text { бесплатного } \\
\text { дошкольного } \\
\text { образования } \\
\text { по основным } \\
\text { образовательн } \\
\text { ым программа }\end{array}$} & $\begin{array}{c}\text { 1. Доля детей в } \\
\text { возрасте 1-6 лет, } \\
\text { получающих } \\
\text { дошкольную } \\
\text { образовательную } \\
\text { услугу и (или) } \\
\text { услугу по их } \\
\text { содержанию в } \\
\text { муниципальных } \\
\text { образовательных } \\
\text { организациях, в } \\
\text { общей } \\
\text { численности детей } \\
\text { 1-6 лет } \\
\end{array}$ & $\%$ & $88 / 90 / 90$ \\
\hline & & & $\begin{array}{c}\text { 2. Доля детей в } \\
\text { возрасте 1-6 лет, } \\
\text { состоящих на } \\
\text { учете для } \\
\text { определения в } \\
\text { муниципальные } \\
\text { дошкольные } \\
\text { образовательные } \\
\text { организации, в } \\
\text { общей } \\
\text { численности детей } \\
\text { в возрасте 1-6 лет }\end{array}$ & $\%$ & $13 / 10 / 10$ \\
\hline & & & $\begin{array}{c}\text { 3. Доля } \\
\text { муниципальных } \\
\text { дошкольных } \\
\text { образовательных } \\
\text { организаций, } \\
\text { оказывающих } \\
\text { дополнительные } \\
\text { услуги }\end{array}$ & $\%$ & $58 / 60 / 60$ \\
\hline
\end{tabular}




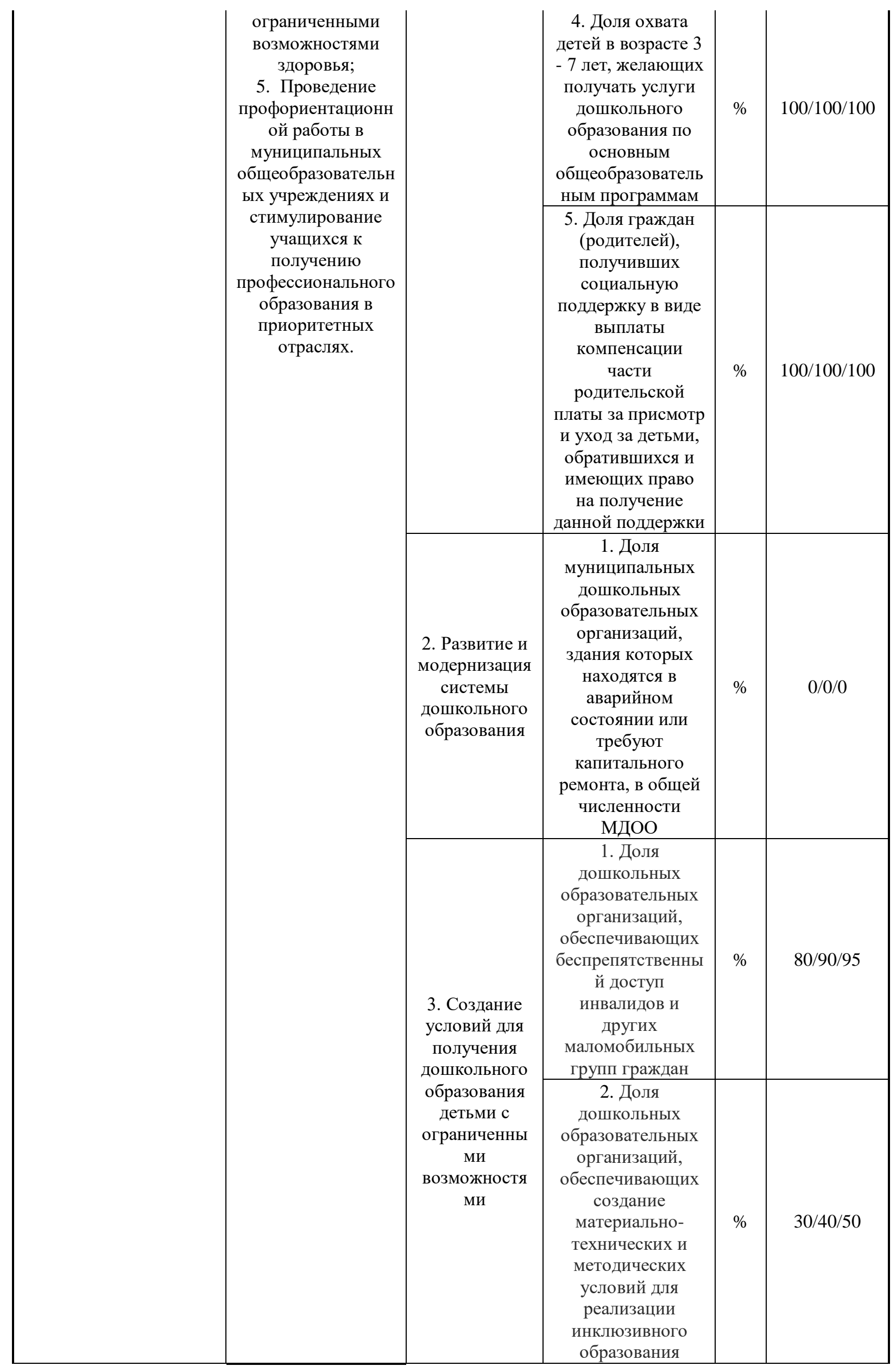




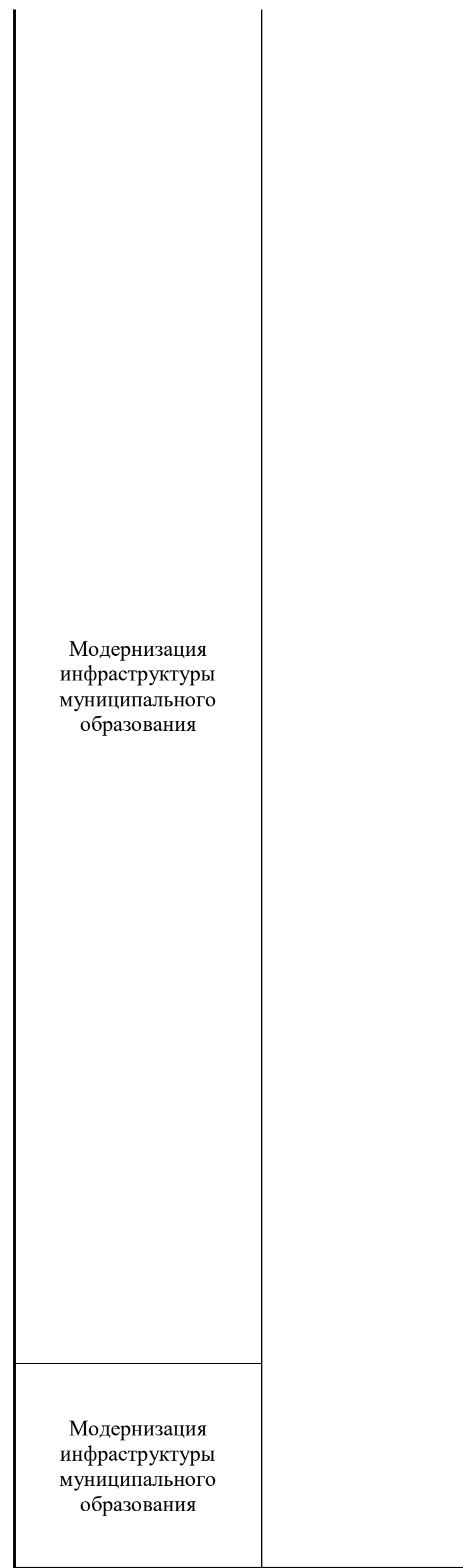

\begin{tabular}{|c|c|c|c|}
\hline $\begin{array}{c}\text { 2. Задачи } \\
\text { Подпрограм } \\
\text { мы } \\
\text { «Развитие } \\
\text { общего } \\
\text { образования } \\
»\end{array}$ & & & \\
\hline \multirow{2}{*}{$\begin{array}{c}\text { 1. Развитие и } \\
\text { модернизация } \\
\text { системы } \\
\text { начального } \\
\text { общего, } \\
\text { основного } \\
\text { общего, } \\
\text { среднего } \\
\text { общего } \\
\text { образования }\end{array}$} & $\begin{array}{c}1 . \text { Доля } \\
\text { муниципальных } \\
\text { образовательных } \\
\text { организаций, } \\
\text { здания которых } \\
\text { находятя в } \\
\text { аварийном } \\
\text { состоянии или } \\
\text { требуют } \\
\text { капитального } \\
\text { ремонта, в общем } \\
\text { количестве } \\
\text { муниципальных } \\
\text { образовательных } \\
\text { организаций } \\
\end{array}$ & $\%$ & $0 / 0 / 0$ \\
\hline & $\begin{array}{c}2 . \text { Доля } \\
\text { обучающихся в } \\
\text { муниципальных } \\
\text { общеобразователь } \\
\text { ных организациях, } \\
\text { занимающихся во } \\
\text { вторую смену, в } \\
\text { общей } \\
\text { численности } \\
\text { обучающихся в } \\
\text { муниципальных } \\
\text { общеобразователь } \\
\text { ных организациях }\end{array}$ & $\%$ & $11 / 8 / 5$ \\
\hline $\begin{array}{c}\text { 2.Создание } \\
\text { условий для } \\
\text { получения } \\
\text { образования } \\
\text { детьми с } \\
\text { ограниченны } \\
\text { ми } \\
\text { возможностя } \\
\text { ми здоровья }\end{array}$ & $\begin{array}{c}1 . \text { Доля } \\
\text { общеобразователь } \\
\text { ных организаций, } \\
\text { обеспечивающих } \\
\text { беспрепятственны } \\
\text { й доступ } \\
\text { инвалидов и } \\
\text { других } \\
\text { маломобильных } \\
\text { групп граждан, в } \\
\text { общем количестве } \\
\text { общеобразователь } \\
\text { ных организаций }\end{array}$ & $\%$ & $\begin{array}{c}32,5 / 33,1 / 33 \\
7\end{array}$ \\
\hline $\begin{array}{l}\text { 3. Задача } \\
\text { подпрограмм } \\
\text { ы «Развитие } \\
\text { доп. } \\
\text { Образования } \\
\text { и воспитания } \\
\text { детей и } \\
\text { молодежи, } \\
\end{array}$ & & & \\
\hline
\end{tabular}




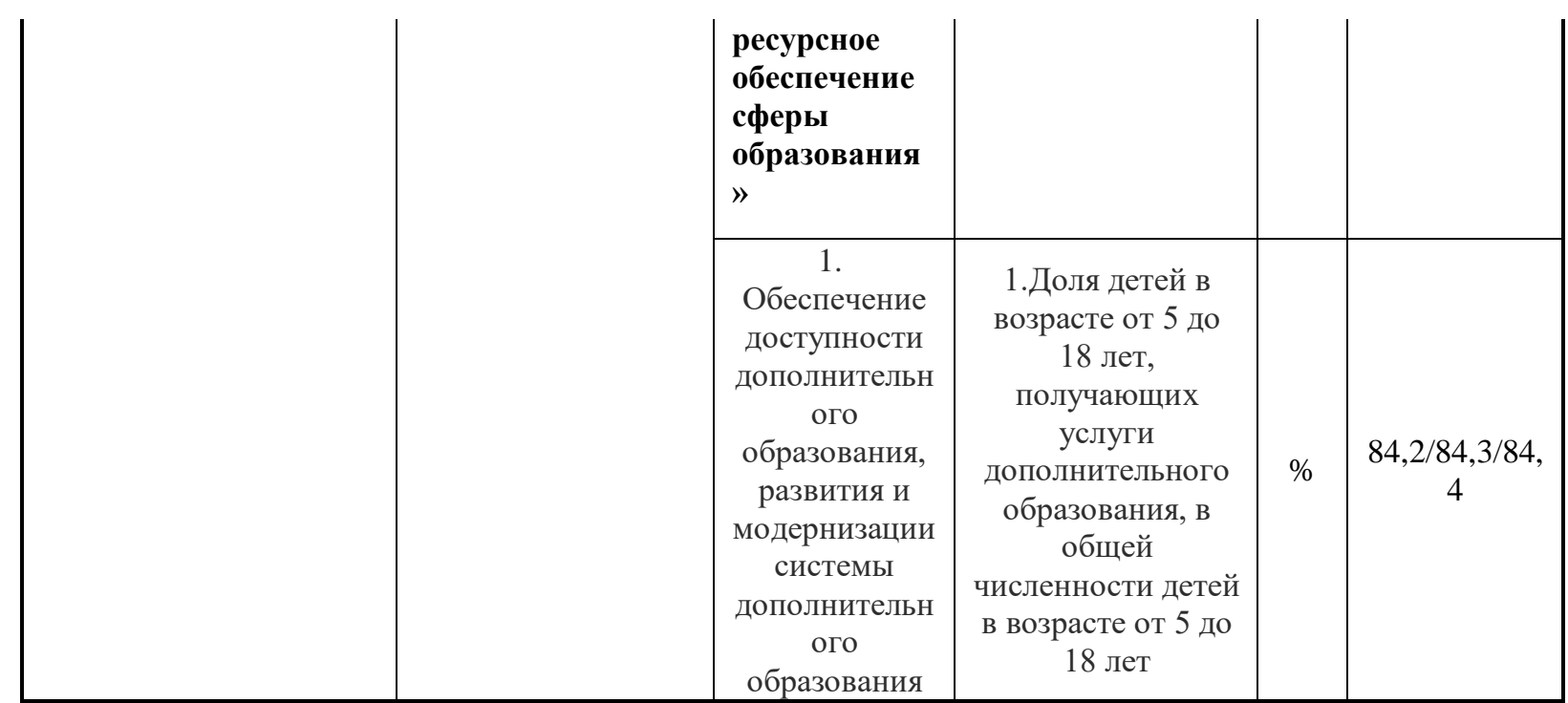

Источник: составлено автором

В Таблице 1. Указаны не все задачи муниципальной программы, а лишь те, которые соответствуют первой задачи Стратегии. Согласно Таблице 1. задачи муниципальных подпрограмм практически соответствуют задачам Стратегии социально-экономического развития муниципального образования. В методике расчета индикаторов используется социологический опрос, анализ статистических данных, периодические и ежегодные аналитические отчеты Департамента образования, данные Росстата. Однако в муниципальной программе развития образования Нижнего Новгорода не определены показатели следующей стратегической задачи «формирование идеологии школы как общественного центра микрорайона, использование образовательных школ как общественных центров для межпрофессионального и межличностного общения». Для реализации данной задачи целесообразно:

1) Разработать план мероприятий, направленных на продвижение муниципальных образовательных услуг (PR-мероприятия, проведение конференций, дней открытых дверей, круглых-столов, открытых лекций как для учеников школ, так и для всех желающих);

2) Стимулировать преподавательский состав к участию в научных конференциях и научной работе в целом;

3) Создавать дискуссионные площадки на базе муниципальных образовательных учреждений;

4) Организовать информационную платформу знаний для осуществления сетевого взаимодействия образовательных учреждений;

5) Привлекать молодых специалистов и преподавательский состав к исследовательской работе.

В качестве индикаторов оценки достижения результатов можно предложить следующие показатели:

1) Количество проводимых конференций, круглых столов, форумов на базе образовательного учреждения.

2) Количество проведенных исследований по запросам органов муниципального управления.

3) Увеличение узнаваемости и степени доверия к школам среди жителей муниципального образования. 
4) Достижение ассоциации школы с общественным центром межличностного общения среди жителей муниципального образования.

5) Разработка механизмов информационного обмена между образовательными учреждениями (как на уровне муниципалитетов, так и региона).

$$
* * *
$$

1. Постановление Администрации города Нижнего Новгорода Нижегородской области «Об утверждении муниципальной программы города Нижнего Новгорода «Развитие образования в городе Нижнем Новгороде» на 2018-2020 годы от 27 декабря 2017 года №6358.

2. Постановление Администрации города Нижнего Новгорода «Об утверждении Стратегии социальноэкономического развития города Нижнего Новгорода на 2017-2022 годы25.01.2017 № 190.

3. Э.Г. Кочетов. Научно концептуальные основы геоэкономической политики России . Москва, «Книга и бизнес». 2010

\section{Землянухина А.C. \\ Роль государственно-частного партнерства в социально-экономической модернизации города}

Воронежский государственный технический университет (Россия, Воронеж)

doi:10.18411/spc-08-04-2018-07

idsp: 000001:spc-08-04-2018-07

Мировой практикой признано, что одним из наиболее эффективных инструментов взаимодействия публичного и частного секторов в решении социальноэкономических задач является государственно-частное партнерство. Единое толкование термина ГЧП отсутствует, но большинство специалистов акцентирует внимание на направленности ГЧП-проектов на решение именно общественно значимых проблем [2].

Государство, приглашая бизнес к сотрудничеству, заинтересовано в использовании присущих частному предпринимательству мобильности, высокой эффективности использования ресурсов, склонности к инновациям.

Сотрудничество с бизнесом предоставляет возможность реализовать весь потенциал социальной ответственности государства и бизнеса в полной мере, улучшив социально-экономический климат в городе.

Участие предпринимателей в рамках осуществления ГЧП-проектов заключается в предоставлении возможности применения сравнительным преимуществом бизнеса и помощи государству и обществу в решении социально значимых проблем [1].

Как всякое новое явление, государственно-частное партнерство пробивает себе дорогу через преодоление непонимания его перспективности и чиновниками, и предпринимателями.

Государственно-частное партнерство - временное взаимовыгодное организационное объединение ресурсов государства и коммерческих структур с целью совместной реализации проектов, имеющих высокое социально-экономическое значение в долгосрочной перспективе.

Если государство обязано быть социально ответственным, то предприниматели в своей деятельности преследуют иную цель: получение прибыли.

Соответственно, основным индикатором социальной ответственности бизнеса выступают уплата налогов и выплата достойной заработной платы.

Однако социальная ответственность не ограничивается оплатой труда. Немаловажными являются снижение уровня безработицы, здоровье и безопасность труда, поддержка малообеспеченных слоев населения, строительство школ и детских садов, борьба с загрязнением окружающей среды и т.д. Важнейшим участником в решении перечисленных проблем призвано быть и предпринимательство [3]. 